\title{
Paleontology and Evolution in the News
}

\author{
Sidney Horenstein
}

Published online: 31 July 2010

(C) Springer Science+Business Media, LLC 2010

\begin{abstract}
This paper is a review of recent publications and journal articles about human evolution and paleontology.
\end{abstract}

Keywords Human evolution · Fossils · Human origins · Survival $\cdot$ Extinction $\cdot$ Paleontology $\cdot$ News media

\section{Review}

In keeping with the rest of this issue devoted to human evolution, this issue's column covers some of the recent media stories and scientific papers related to human fossils and evolution. We will start with the opening and a few reviews of the new hall of human evolution at the Smithsonian Institution, the David H. Koch Hall of Human Origins. The new exhibit, which celebrates the 100th anniversary of the museum on the National Mall, is based on a decade of cutting-edge research by Smithsonian scientists and is the result of an international collaboration with over 60 research and educational organizations and over 100 researchers from around the world. The exhibit "offers an immersive, interactive journey through 6 million years of scientific evidence for human origins and the stories of survival and extinction in our family tree during times of dramatic climate instability," according to the museum's website. http://www. mnh.si.edu/calEvents/Summer_2010_Event_Calendar.pdf The new exhibit opened March 17 in a 15,000-square-foot space. As one might expect, the exhibit was reviewed by a large number of newspapers and other outlets. Here are the

S. Horenstein $(\triangle)$

American Museum of Natural History,

Central Park West at 79th Street,

New York, NY 10024, USA

e-mail: horenst@amnh.org sources of a small sample of reviews: The New York Times (http://www.nytimes.com/2010/03/19/arts/design/19museum. html) "Searching Bones of Our Shared Past" by Edward Rothstein, The Washington Post (http://www.wash ingtonpost.com/wp-dyn/content/article/2010/03/18/ AR2010031800820.html) "Smithsonian's Natural History Museum opens its Hall of Human Evolution" by Michael O'Sullivan, The Voice of America (http://www1.voanews. com/english/news/science-technology/Smithsonian-OpensNew-Exhibit-on-Human-Origins-91541824.html) "Smithsonian Opens New Exhibit on Human Origins" by Rosanne Skirble; PBS NewsHour (http://www.pbs.org/newshour/rundown/2010/04/exhibit-asks-what-does-it-mean-to-be-hu man.html) "Natural History Exhibit Asks: 'What Does it Mean To be Human?"' by Murrey Jacobson, and in The Wall Street Journal (http://online.wsj.com/article/SB1000 $1424052748704446704575206081151018608 . \mathrm{html}$ ?mod= WSJ_latestheadlines) "Our Species Rediscovers Its Cousins" by Julia M. Klein. In The Wall Street Journal review, one of the best, the author comments that it is startling to learn that, as recently as 70,000 years ago, there were at least four human species that coexisted including the tenacious, longlived Homo erectus and diminutive, hobbit-like Homo floresiensis found in Indonesia in 2009. The sensational 1974 discovery in Ethiopia of "Lucy," resembling an ape but walking upright, placed human origins 3.2 million years ago. The fabulous store of fossils in these deposits has given up even older erect-standing ancestors as far back as six million years ago. At this time, there are more than 6,000 human fossils - a collection which at the time of their individual discoveries forced revisions of old timelines and theories. So our species, Homo sapiens, seems to have had an abundance of long-lived cousins providing the basis for the ongoing discussion of how they are related to each other. The new exhibit at the Smithsonian National Museum of Natural 
History provides an overview of this ongoing investigation into human origins. In addition to reviewing the substance of the exhibit, Ms. Klein comments on the exhibit presentation itself. Dull browns and the lack of natural light in the \$20.7million hall mean it "is not the greatest-looking space. Its exhibits contain enough repetition to suggest that they could have been made more compact." In addition, she suggests that the near lack of actual specimens diminishes "the sense of wonder the real thing always inspires." But the real things are extremely fragile, and placing them on display not only makes them unavailable for study but also may jeopardize their integrity. "Overall, though, the Hall of Human Origins is an educational triumph. With lucid labels and a wellconceived mix of art, touchable casts, video, and touchscreen computers, the hall ably explains the state of the science and manages the often-elusive feat of engaging both children and adults." The halls contain two major themes: What does it mean to be human? And how did climate change affect human evolution? "It's long been accepted that different human species were adapted to thrive in specific climatic niches. Neanderthals had short, compact bodies to conserve heat and large nasal passages to warm frigid air, while our African forebears had long, skinny frames suited to hotter climes. But this exhibition contends that the evolutionary concomitant of incessant climate change was human resilience - the flexibility to make it almost anywhere, thanks to large, sophisticated brains and social networks." Thus, just as today, versatility was characteristic of our oldest relatives. "Walking upright did not preclude climbing trees and this characteristic is strikingly made clear in the diorama of 'Lucy' (Australopithecus afarensis) where she has one foot on the ground and one on a limb symbolizing her straddling of the two environments." The reviewer was also impressed with other aspects of the exhibit, for example, "John Gurche's remarkable forensic reconstructions of a variety of early humans." Included in the exhibit are free-morphing stations, where visitors snap photographs, watch themselves acquire early-human features, and e-mail them home. "The most innovated, effective exhibits, 'Snapshots of Survival,' cleverly merge old and new: simulated fossil beds with casts, interactive video featuring museum scientists, and animations...the three presentations illuminate the tales that bones and artifacts tell, allowing us, in a modest way, to play anthropologist."

Educators and anyone else interested in human evolution who cannot visit the museum will be gratified to know that an extensive website has been made available by the Smithsonian (http://humanorigins.si.edu/). The website is divided into six major sections: Human Evolution Evidence, Human Evolution Research, Human Characteristics, Exhibit, Education, and Resources. Within each segment are clear and abundant illustrations and photographs as well as text to support the introduced concepts. For example, the segment on Human Evolution Evidence is subdivided into the following categories: Behavior, 3D Collection, Human Fossils, Genetics, Dating, and Timeline Interactive. The Behavior segment is further divided into Primate Behavior, Footprints, Stone Tools, Getting Food, Carrying \& Storing, Hearth \& Shelter, Burial, Recording Information, Making Clothing, and Art and Music. In keeping with this journal's education and outreach mandate, it would be remiss not to include the education segments: Teachers Forum, Education Network, Lesson Plans, Educators Guide, For Students, and Fun Facts. Included is an "Educators Guide for Grades 5$12, " 41$ pages in PDF format that can be downloaded and is worth a look. Although it is prepared as a guide to the exhibit, there is enough material provided to make the effort to retrieve it useful even if a visit to the museum is not possible. There is enough material on this website that can be used as the basis for at least a semester course in human evolution, and it is a model for what an educational website can strive to be.

The Wall Street Journal also published a Saturday Essay, "Humans: Why They Triumphed" on May 22, 2010 (http:// online.wsj.com/article/SB10001424052748703691804575 254533386933138.html) by Mark Ridley, an author who writes about evolution and genetics. "How did one ape 45,000 years ago happen to turn into a planet dominator? The answer lies in an epochal collision of creativity." Here is part of what he wrote about the puzzle of human evolution, which is that "Nothing seems to explain the sudden takeoff of the last 45,000 years... all of the ingredients for human sucess...seem to have been in place a half-million years before, and nothing happened." Why did culture explode in Africa? "The answer lies in a new idea, borrowed from economics, known as collective intelligence: the notion that what determines inventiveness and rate of cultural change of a population is the amount of interaction between individuals." He believes that scientists have been looking in the wrong place. "Most have been expecting to find a sort of neural or genetic breakthrough that sparked a 'big bang of human consciousness,' an auspicious mutation so that people could speak, think, or plan better..." Continuing the thought, he proposes that "the sophistication of the modern world lies not in individual intelligence or imagination [but in] collective enterprise..... [And] once human progress started, it was no longer limited by the size of human brains. Intelligence became collective and cumulative."

You may recall that in 2009 a fossil named Ardi received worldwide attention. To summarize, it was to be a scientific breakthrough. First discovered in 1992, Ardipithecus zamidus, the 4.4 million-year-old female skeleton took 17 years for scientists to reconstruct and analyze the remains. Numerous articles followed including a special Discovery Channel program: "Discovering Ardi." The discovery of the skeleton rewrites the story of human 
evolution and provides strong evidence that bipedality is the oldest defining characteristic of human ancestors. The Discovery Channel posted several videos about Ardi, including the Ardipithecus Handbook, an "interactive guide to the oldest skeleton from our branch of the primate family tree." Notable in the presentation is how the skill of scientific illustrator Jay Matternes gave face and form to Ardi. Also worth looking at is the extensive article in the New York Times on October 2, 2009 by John Noble Wilford, "Fossil Skeleton From Africa Predates Lucy" (http://www.nytimes.com/2009/ 10/02/science/02fossil.html) as well as the October 2, 2009 issue of Science (http://www.sciencemag.org/ardipithecus/) which contains 11 papers by a diverse international team of scientists and is free to download.

Now a number of critics have published in the journal Science for May 28, 2010 reevaluations of the original interpretations, among them Thure E. Cerling et al. "Comment on the Paleoenvironment of Ardipithecus ramidus" (http://www.sciencemag.org/cgi/reprint/328/5982/ 1105-d.pdf). For comparison also, here is the reference to a John Wilford Noble update article in the New York Times for May 27, 2010, "Scientists Challenge 'Breakthrough' on Fossil Skeleton" (http://www.nytimes.com/2010/05/28/sci ence/28fossil.html?ref=john_noble_wilford): “The fossil skeleton known as Ardi, hailed in some quarters as the scientific 'breakthrough' of 2009, has now drawn critics who dispute the claims" that the species lived in a dense woodland rather than grassy open plains. Grassy plains have long been interpreted as the probable habitat of early prehumans, a habitat that perhaps created the environment that stimulated the impetus for upright walking. Also challenged was the interpretation based on fossil material that Ardi was a member of the human lineage. In other words, Ardi appeared after the divergence from African apes. But the challenge is that the primitive anatomy indicates it is a species that came before the common ancestor of the human and chimpanzee family trees. Thure E. Cerling, a geochemist at the University of Utah, and seven additional geologists and anthropologists dispute the woodland scenario. Using data from the original teams' study of the soil and silica from ancient plants, they conclude that the environment can be described as a tree or bush savanna, that is, a grassland with about 25 percent tree canopy. They describe a woodland environment as one that contains 60 percent or more trees and shrubs. This is important because savannas are associated with the evolution of the upright walking characteristic that sets humans apart from ancestral apes. Francis H. Brown, also a Utah geologist and co-author of the paper, said in an interview, "We are trying to set the record straight—we don't think open savanna grassland is what Ardi lived in, nor is it a closed woodland environment." Esteban Sarmiento challenged the identification of Ardi as a hominid - a species of the human lineage that arose from an ancestor in common with the branch leading to modern chimpanzees. He said Ardi's skeleton contains primitive aspects and that molecular and anatomical studies suggest that Ardi predates the humans of Africa. A few anthropologists, such as Richard S. Klein of Stanford University, said in an interview, "I frankly don't think Ardi was a hominid or bipedal." A middle ground was expressed by Daniel E. Lieberman, a paleoanthropologist at Harvard, who said "he was convinced that Ardi is a hominid." Everybody has questions about the kind of hominids it is and about what this has to say about the last common ancestor of hominids and chimps. Tim D. White of the University of California, who led the team that discovered the fossils in 1992, said that the interpretation "was bound to generate some give and take. So from that point of view, this is just part of normal science." In a published response, Dr. White said that the critics ignored "the totality of the fossil, geological and geochemical evidence." He said that there was a grassland at the site, but the abundant fossils there were mammals adapted to woodland life, and this established Ardi as "a denizen of the closed habitat," not the open savannas. Regarding the objections based on biomolecular estimates of the hominid -ape divergence as 3.5 million years ago, these dates are unreliable. Other fossil discoveries have pushed the divergence back sometime before six million years ago.

On May 8, 2010, Google News (http://news.google.com/ news/) reported that 469 articles and stories appeared in a variety of news outlets about the "Neanderthal in all of us" in the first two days of its release. The scientific study discovered that humans living today have Neanderthal genes and that for some people it is up to four percent. Not only was the story compelling but there were considerable materials available for use by the media. The scientific paper was published in Science on May 7, 2010 by Richard Green et al. (http://www.sciencemag.org/cgi/content/full/ 328/5979/710), "A Draft Sequence of the Neandertal Genome," accompanied by a special section, which turns out to be not only a treasure trove for the news media but also for teachers and students. The special section is composed of four parts, each one of which includes a video commentary from the senior author and director of the Neanderthal Genome Project, Svante Paabo, and also geneticist Sarah Tishkoff (University of Pennsylvania) and paleoanthropologist Chris Stringer (Natural History Museum, London) as well as a timeline of discoveries and a collection of related articles and websites. Part 1: Background includes a map of the range of Neanderthals from Europe to southern Siberia and the Middle East and a graphic of a timeline of discoveries starting with the first fossils of Neanderthals discovered in 1829 in Engis, Belgium. Included with the timeline are references to the discoveries. Neanderthals (Homo neanderthalensis) are 
currently believed to be our closest evolutionary relatives, who first appeared in the fossil record about 400,000 years ago and disappeared about 30,000 years ago. The website also directs the reader to the full text of "A Neandertal Primer" by Michael Balder, published in Science, February 13, 2009, vol. 323, no. 5916, page 870 (http://www. sciencemag.org). This one-page summary provides concise answers to ten questions that students would ask such as: When and where did they live? How are they related to modern humans? What did they look like? Could they talk? And why did they go extinct? Part 2: Methodology discusses the process of sequencing the Neanderthal genome and the difficulties of extracting and analyzing the ancient DNA. To make the comparisons, the genomes of five present-day individuals from different parts of the world - southern Africa, West Africa, Papua New Guinea, China, and western Europe-were compared to the genomes of the Neanderthal and a chimpanzee. Part 3: Human-Neanderthal Comparison examines the evidence of admixture and implications for human origins. The findings that Neanderthals are on average closer to individuals in Eurasia than to individuals in Africa present a challenge to the strictest version of the "Out of Africa" model. Part 4: Related Resources includes papers published in Science, as well as additional commentaries by the researchers and a list of excellent web resources. The MailOnline (http:// www.dailymail.co.uk/sciencetech/article-1273904/) reported the discovery by indicating that Neanderthal man is "alive and well-and is living happily in Britain...." David Derbyshire writes that the study "found that our ancestors couldn't resist the charms of the Neanderthals tens of thousands of years ago." The result is that "Neanderthal genes have been passed down to us today." (Here one should note that the spelling of Neandertal in the scientific papers is referred to above as in this sentence, but in this and other articles, it is spelled as Neanderthal, which is probably the result of the spelling that is found in word processing spell checkers.) However the results of the study "showed that up to four percent of the DNA of non-African people alive today is Neanderthal....The two species lived alongside of each other in Europe and Asia until Neanderthals vanished around 30,000 years ago, possibly driven to extinction by the smarter and more competitive modern humans." Professor Paabo said, "Since we see this pattern in all people outside of Africa, not just the region where Neanderthals existed, we speculate that this happened in some population of modern humans that then became the ancestors of all present-day non-Africans. The most plausible region is in the Middle East where the first modern humans appeared before 1,000,000 years ago and where there were Neanderthals until at least 60,000 years ago." The article includes excellent downloadable images including a group of early humans dressed in furs that came from a scene in a film, some of the Neanderthal bones used in the study, Dr. Svante Paabo with a reconstructed Neanderthal skull, an annotated map of the interaction of modern humans and Neanderthals, and a labeled skeleton of a modern human and a Neanderthal skeleton. Nicholas Wade wrote the story for the New York Times, "Signs of Neanderthals Mating with Humans" (http://www.nytimes. com/2010/05/07/science/07neander thal.html), which contains an image of the Vindija Cave in Croatia where the three Neanderthal bones were found. The researchers report that Neanderthal DNA does not seem to have played a great role in human evolution. Scientists, however, believe that the human genome sequence they are decoding (about 60 percent up to this time) will be of extraordinary importance because it will lead to an understanding of human evolutionary history. The article quotes Dr. Ian Tattersall, a paleontologist at the American Museum of Natural History in New York, referring to the genome study described in Science, "This is a fabulous achievement.... This is probably not the authors' last word, and they are obviously groping to explain what they have found." But he and other archeologists questioned some of the interpretations put forward by Dr. Paabo and his chief colleagues, Richard Green of the Leipzig Institute and David Reich of Harvard Medical School. "Geneticists have been making increasingly valuable contributions to human prehistory, but their work depends on complex mathematical statistics that make their arguments hard to follow." Extra precautions were undertaken not to contaminate the DNA sequences by human DNA, which apparently happened in previous studies. These studies show that it is incorrect that everyone comes from the same population out of Africa. Robert Lee Hotz wrote the story for The Wall Street Journal (http://online.wsj.com/article/SB 10001424 052748703686304575228380902037988.html) on Friday, May 6, 2010, which contains a photo of Svante Paabo in an excavation in the cave in Spain and other images. He reported that "Most People Carry Neanderthal Genes." Although previous studies, based on more fragmentary genetic samples, did not find any evidence that Neanderthals left any traces in the modern human genome, the new findings are based on new technology along with powerful computational statistical tools and other techniques to divulge the genetic makeup. From the attained pattern, the researchers deduced that prehistoric humans encountered their Neanderthal mates in the Middle East as small human bands first migrated out of their African homeland. "A little interbreeding would have spread those genes far and wide," said British Anthropologist Chris Stringer of London's Natural History Museum. "Their laboratory work is impeccable," said molecular anthropologist Todd Driscoll at New York University, who studied the findings but was not involved in the project. 
"Seafood diet behind big brains" is the headline in Times of India, June 11, 2010, (http://timesofindia.indiatimes. com/articleshow $/ 5998115 . \mathrm{cms}$ ) reporting on a study published in the Proceedings of the Natural Academy of Sciences (PNAS) for June 1, 2010, vol. 1017, no. 22, pp. 10002-10007 (http://pnas.org/cgi/doi/10.1073/pnas.1002 181107) "Early hominin diet included diverse terrestrial and aquatic animals $1.95 \mathrm{Ma}$ in East Turkana, Kenya" by David R. Braun et al. This team of scientists from Kenya, the United States, the U.K., Australia, and South Africa discovered a 1.95 million-year old site in northwestern Kenya in 2004. The site is located in the northern part of the Koobi Fora Formation on the eastern side of Lake Turkana in northern Kenya. It provides the oldest in situ evidence that hominins predating $H$. erectus feasted on the carcasses of terrestrial and aquatic animals they butchered in a well-watered habitat. Preservation of the excavated site was so remarkable that the team was able to develop a detailed reconstruction of the environment. Over four years, the scientists excavated thousands of fossilized bones and stone tools and were able to determine that at least ten individual animals, and perhaps many more, were butchered by early humans at this site. Many of the bones showed evidence of cut marks made by early human ancestors as a result of using sharp stone tools to cut meat from the bones or crush long bones to access the fat-rich bone marrow. In an interview, the lead author of the research, David Braun of the University of Cape Town in South Africa said, "At sites of this age we often consider ourselves lucky if we find any bone associated with stone tools, but here we found everything from small bird bones to hippopotamus leg bones." The study of the plants at the site revealed that the environment these early humans were living in was wet and probably marshy. These early humans were relatively small and not suited to compete with the large carnivores that lived at that time. "Gaining access to smaller animals like turtles and fish may have allowed these early human to increase the protein in their diet without the danger of interacting with dangerous carnivores, such as lions and hyenas." Thus living in an area with brain-fueling food may have been a fortunate side effect of finding foods at lakes and rivers. "Lead zooarcheologist Jack McCoy of Rutgers University identified bones of various animals including turtles, fish, crocodiles and large antelopes that ended up as the meals of these early humans." Although animal tissues provide nutrient-rich fuel for the growing brain, aquatic resources (e.g., fish, crocodiles, turtles) are especially rich sources of the long-chain polyunsaturated fatty acid and docosahexaenoic acid that are so critical to human brain growth. "Therefore, the incorporation of diverse animals, especially those in the lacustrine food chain, provided critical nutritional components to the diets of hominins before the appearance of $H$. ergaster/erectus that could have fueled the evolution of larger brains in Late Pliocene hominins.... The presence of overlying layers of volcanic ash helped the team pin down the ages of the site." Geologists on the team used a combination of techniques to estimate the age of the site as close to 1.95 million years. Reporting by the National Geographic Society on June 2, 2010 (http://news.national geographic.com/news/2010/06/ 100602-early-humans-evo lution-crocodiles-big-brains-science/) used a catchy headline, perhaps to entice one to read it, "Eating Crocodile Helped Boost Early Human Brains?" Not quite the same emphasis as other reports, but the article went on to say briefly and succinctly that the animal bones bore cut marks from simple, sharp-edged stone tools and that this early hominin diet is what may have boosted brain size. The article reports that Dr. Braun indicated Kenyan hominins were no crocodile hunters. "Instead, early humans likely scavenged carcasses, bringing the meat back to the kitchen to carve up and-in the pre-fire era of human history-eat raw."

The next article, "Humans evolved to walk upright "because it was hot near the ground," was by Niall Firth in MailOnline for June 10, 2010 (http://www.dailymail.co.uk/ sciencetech/article-1285270/New-evidence-humanswalked-upright-hot.html). Interest peaked almost immediately, and in a short time there were 31 published news stories - here are some other headlines derived from the paper cited below by Benjamin Passey and others:

"Did humans evolve to be long-distance runners. No."

"Ancestors of humans learned to walk in trees."

"Pre-humans in Africa evolved to beat the heat."

"We evolved to walk on heels in order to save energy while out hunting-gathering."

"Humans learned to walk on two legs because it's more efficient."

"Bipedal humans descended from trees, not up from the ground."

An article by Emily Sohn in Discovery News, June 11, 2010, "Why Humans Have No Fur-Explained" (http:// news.discovery.com/human/humans-lost-fur-hot-climate. html) ascribes the furless condition of our ancestors to the fact that, because they lived somewhere really hot, it would have made sense for us to lose body hair, start sweating more, become slender, and even walk upright to create distance between our bodies and the hot ground. A study by Benjamin H. Passey, a geochemist at Johns Hopkins University, and his colleagues show that the key cradle of human evolution in East Africa has indeed been really hot for at least four million years. To find out how hot it was in the past, the scientists analyzed dated soil samples from the Turkana Basin in Kenya. It turns out that as temperature drops, a rare carbon isotope, carbon-13, tends to clump together with a rare isotope of oxygen, oxygen-18, within 
the soil. Through a fairly simple relationship, the more clumping together these scientists detect, the colder the temperature the samples were formed in. The results show that the soil in the Turkana Basin has remained over 85 degrees Fahrenheit with spikes above 95 degrees Fahrenheit over the past four million years. Today the air temperature in the Basin regularly exceeds 100 degrees Fahrenheit, with nighttime temperatures in the 70 s creating a landscape sparse in grasses, shrubs, and bushes. Given this unrelenting heat today, one would think that had humans evolved here, the area would have been a much nicer, lusher place. But the study shows that it was just as hot. Passey said that "No one knows for sure when we became proficient at sweating and when we lost our fur." See Benjamin Passey and others on "High Temperature Environments of Human Evolution in East Africa Based on Bond Ordering in Paleosol Carbonates" in Proceedings of the National Academy of Sciences (PNAS), vol. 107, no. 25, pp. 11245-11249 (http://www.pnas.org/content/107/25/ 11245.full.pdf + html).

A fragment of flint believed to be carved by human hand that was found at Westcliff High School for Girls in Westcliff-On-Sea was reported by The Sun, June 21, 2010 (www.Thesun.co.uk/sci/homepage.news/3022555/html). Ken Crowe, an archeology expert at the Central Museum, said, "The flint is very small, only about one inch or so long. But it's the earliest evidence we have of occupation in Essex, England." It is believed to have been used by a species of human known as Boxgrove Man, the remains of which were first found in a quarry near Chichester, West Sussex, in 1993. It is believed to be the second oldest discovery pointing to human settlement in the country. The oldest discovery, in 2000, was in Pakefield, Sulfolk, dating back about 700,000 years. "The discovery means early humans were living here before the River Thames took on its present form." Originally, the Thames flowed in a more northerly direction, but during the glaciation the river was diverted southwards to its present location. Boxgrove Man, or Homo heidelbergensis, is believed to have lived in groups and roamed the countryside hunting and scavenging for food.

A number of new hominid fossils have been found at the UNESCO World Heritage site called the "Cradle of Humankind" because it harbors a large number of hominid fossils, including some of the oldest, dating back to 3.5 million years ago. Located about 35 miles northwest of Johannesburg, South Africa, in Gauteng Province, the region is composed of a series of dolomitic limestone caves spread over about 180 square miles. Even those with a limited knowledge of human paleontology will probably recognize the cave names Kromdraai, Sterkfontein, and Swartkrans. Not only are these caves famous for hominid fossils, they have yielded numerous fossilized remains of animals and plants. Originally coral reefs, the calcitic limestone was converted in part to dolomite; then after geological uplift, groundwater dissolved the calcitic material to form caves that often display stalagmites and stalactites, as well as shafts that reached the surface. Plants, animals, stones, and hominids all fell into the caves with no real exits and became trapped and died. More than 850 hominid fossils remains have been found at the cave sites, perhaps the richest concentration of such fossils. Following are two recent discoveries from the Cradle of Humankind.

On May 26, 2010, National Geographic News posted the following article by James Owen, "Oldest Human Species Found: May Have Been Cannibal?" (http://news. nationalgeographic.com). He writes that there is a good chance it was a tiny little cannibalistic tree swinger, but the newly identified Homo gautengensis is family, our family, according to a new study. "The creature is the oldest named species in the human genus, Homo," says study author Darren Curnoe, anthropologist at the University of New South Wales, Australia. The new species designation is based on pieces of skull, jaws, teeth, and other bones found at the Sterkfontein caves complex. Although the skeletal parts are fragmentary, the author believes that $H$. gautengensis walked upright, was three and a half feet tall, and weighed about 110 pounds. Media reports on the story include those from the Herald Sun, May 28, 2010, (http:// www.heraldsun.com.au) and the MailOnline (http://www. dailymail.com.uk), but by mid-June, 2010, the story was no longer available to view on the National Geographic website at the time of this writing. The new species emerged more than two million years ago and died out approximately 600,000 years ago. Marks on the skull show "that it was de-fleshed, whether for ritual burial or cannibalistic consumption.... Along with burial bones, the marks suggest that man was certainly on the menu of Homo gautengensis." Although the new species had teeth apparently adapted for eating plant material, it evidently also ate meat. Compared with modern humans, the new species had proportionately long arms, a projecting face somewhat like a chimp's, large teeth, and a smaller brain - although not too small for verbal communication. Dr. Curnoe said in an interview, "while it seems possible that Homo gautengensis had language it would have been more rudimentary than ours, lacking the complex tones and lacking a grammar, as all human languages have." For further information about this species, probably the earliest recognized species in the human genus, refer to "A Review of Early Homo in Southern Africa Focusing on Cranial, Mandibular and Dental Remains," with the description of a new species (Homo gautengensis sp. nov.) in HOMO-Journal of Comparative Human Biology, vol. 61, pp. 151-177 (http://www.elsevier/de/jchb) by D. Curnoe. 
Also from the Cradle of Humankind is the discovery of two skeletons, a young male and an adult female-a new species, Australopithecus sediba. Studies of the skeletons indicate that this new species walked upright and shared many physical traits with the earliest known human species. Named Karabo after a naming competition that included 15,000 submissions, the 1.95 million-year-old juvenile male is thought to have been between nine and 13 years old when he died. Mali Wiederkahr is one of the numerous writers who reported on this discovery. The article appeared in The Johns Hopkins Newsletter (http://media.www.jhu newsletter.com/media/storage/paper932/news/2010/04/22/ ScienceTech/New-Hominid.Ancestor.Among.First. To. Walk.Upright-3912389.shtml) on April 22, 2010. "Lee Berger, a paleontologist at the University of Witwatersrand and the lead author of the scientific study, believes that Australopithecus sediba is either an ancestor of Homo or a member of a close branch of Homo." One of the reasons some anthropologists argue against this interpretation is that the male skeleton was young and had not reached its mature growth, indicating that the skeleton might not be an accurate representation of the species as an adult. "Another reason to believe that $A$. sediba is not a Homo ancestor is that Homo species were already established before $A$. sediba emerged." According to the paper, the first known Homo species emerged 500,000 years before A. sediba. The research was published in Science, April 9, 2010, vol. 238, pp. 195-204 (http://sciencemag.org). The paper's abstract reads: "Despite a rich African Plio-Pleistocene hominin fossil record, the ancestry of Homo and its relation to earlier australopithecines remain unresolved. Here we report on two partial skeletons with an age of 1.95 to 1.78 million years. The fossils were encased in cave deposits at the Malapa site in South Africa. The skeletons were found close together and are directly associated with craniodental remains. Together they represent a new species of Australopithecus that is probably descended from Australopithecus africanus. Combined craniodental and postcranial evidence demonstrates that this new species shares more derived features with early Homo than any other australopith species and thus might help reveal the ancestor of the genus." The article contains a few excellent illustrations that can be used in the classroom.

In the same issue of Science on pages 154-155, Michael Balter reviews some of the claims made by the team in "Candidate Human Ancestor From South Africa Sparks Praise and Debate." The big one, he states, is that the authors believe that the new species may be the best candidate yet for the immediate ancestor of our genus, Homo. "Few scientists are ready to believe it themselves just yet." So are the new fossils Homo ancestors or a side branch? That remains to be seen, but researchers agree the well-preserved fossils offer vital new clues to a murky area in human evolution. Meave Leakey of the National Museums of Kenya, Nairobi, says, "They are a remarkable find" and thinks the species is an australopithecine, while William Kimbel of Arizona State University, Tempe, thinks they are "very lovely specimens" and they are a species of Homo. Balter says such different views of how to classify these fossils reflect a still-emerging debate over whether they are part of our own lineage or belong to a southern African side branch. Paleoanthropologist Donald Johanson, also of Tempe, says, "The transition to Homo continues to be almost totally confusing." Others indicate that the characteristics shared by $A$. sediba and Homo are few and could be due to normal variation among australopithecines. Tim White of the University of California, Berkeley, and others also think the "new fossils might represent a latesurviving version of $A$. africanus or a closely related sister species to it, and so will be chiefly informative about that lineage." The research team "thought long and hard about putting the fossils into Homo but decided that given the small brain and other features, the hominin was australopithecine-grade."

In the same issue of Science (vol. 328, pp. 205-208, April 10, 2010), Paul H.G.M. Dirks and others in the "Geological Setting and Age of Australopithecus sediba from Southern Africa" describe the Malapa Cave, containing the Plio-Pleistocene deposits from which the new species was retrieved. The cave is formed in a stromatolite-rich dolomite of Late Archaean Age, 2.642.50 billion years old, much like the other caves in the Cradle of Humankind. The Malapa was formed at the intersection of two fractures in which there are vertical shafts that formed deathtraps. Deposits within the cave are cone-shaped accumulations of debris transported to a final resting place within the cave by the flow of water, perhaps from a storm, burying the fossils found in the ten-foot-deep excavation. The superb preservation of the skeleton indicates rapid burial, limited transport distance, and most importantly, out of the reach of carnivores. Chemistry of the debris flow, laminar in structure, indicates that cementation occurred soon after deposition. In addition to the hominids, 209 nonhuman fossil specimens were collected that represent a macro fauna assemblage that existed in Africa between 2.36 and 1.50 million years ago. The deposit rests on a flowstone that has been dated as $2.026 \pm 0.021$ million years old. The two hominin specimens were buried together in a single debris flow. 